\title{
Shape Grammars for Creative Decisions in the Architectural Project
}

\author{
Joana Tching ${ }^{1, *}$ Joaquim Reis ${ }^{2}$, Alexandra Paio ${ }^{2}$ \\ ${ }^{1}$ ISCTE-IUL Institute University of Lisbon, Portugal \\ ${ }^{2}$ ISCTE-IUL Institute University of Lisbon, ADETTI-IUL, Portugal
}

Copyright $@ 2017$ by authors, all rights reserved. Authors agree that this article remains permanently open access under the terms of the Creative Commons Attribution License 4.0 International License

\begin{abstract}
Shape grammars (SG), which define a set of shapes, are used in applications in the field of Computational Creativity (CC). Computational Creativity can be considered an area of Artificial Intelligence (AI) that chases the goal of understanding creativity and building computational applications that emulate or support human creativity in Arts and Science. In this context, our aim is to show how SG may provide artists with applications to assist them in the creative process, not only creating solutions but also as a way of creating new ideas. Our objective is to demonstrate how, in architecture, SG can work with rules that will convey legal restrictions, space needs and goals of the architect, creating possible solutions to a project. A wide range of solutions can be tested in computational applications based in SG. These applications can also encourage the architect to go further in his creativity through shape emergence where the conditions are fulfilled and presented as innovative and/or unexpected. Architects obey strict rules when they apply artistic intention to a specific need/objective intention (space building). Thus, our methods are to enumerate SG as a tool for decision-making in architectural projects and to show a set of common phases that may be generated by the use of computational applications in response not only to technical needs but also to creative goals.
\end{abstract}

Keywords Shape Grammars, Computational Creativity, Architectural Project

\section{Introduction}

Shape grammars are used in applications in the field of Computational Creativity (CC). Basically, CC can be considered an area of Artificial Intelligence (AI) that chases the goal of understanding creativity and building computational applications that emulate human creativity in Arts and Science. Combining knowledge of AI with other areas of knowledge, such as cognitive psychology, and philosophy, CC intends to emulate or support human creativity using a computer. Computational Creativity contributes to the artwork through new forms of interaction with digital information, producing effects that stimulate human perception and potentiate the artist's creativity, allowing the artist to obtain a wider range of new solutions [1].

Historically, SG were conceived in the 70s by George Stingy and James Gips [2] and arose when AI was already studying different areas of knowledge and when the first graphic computational editor appeared [3]. This later can be considered the precursor of CAD (Computer-Aided Design) systems. Shape grammars are part of one area of knowledge called "Design Computing” or "Computational Design". They are production systems that allow the generation of compositions with shapes or designs [4].

From those early beginnings, SG now have capacity for synthesis and analysis of styles of design / architecture / art and allow the creation of new forms integrated in a specific language or the definition of new languages $[5,6]$, their use in design through computer applications enables the designer to incorporate the unique capabilities of the human mind and those from AI. This combination and the applications that allow it are examples of CC. This way, a synergy between two partners will be produced. Design will be generated not only through formalism and rationalization but also through intelligence and creativity [7]. Our aim is to show how SG may provide artists with applications to assist them in the creative process, not only creating solutions but also as a way of creating new ideas.

The components of SG are basic shapes, named the "shape alphabet" and a set of condition-action rules that define the ways of combining shapes, according to the space relationships among them. They are a way of generating designs through the use of initial shapes and rules that have their roots in the production system of a mathematician named Emile Post [8] and in the generative grammar of linguist Noam Chomsky [9]. Shape grammars are similar to phrase structure grammars, dealing with an alphabet of 
shapes that, generically, generate n-dimensional shapes. In the context of SG, besides the use of purely algorithmic processes related to representation and computation with shapes, there are large amounts of specific knowledge concerning the exploration of the design languages that must be represented and organized [10]. This is accomplished through the definition of a set of rules that combine the technical and creative purposes of the architect. Computational applications that use SG can be used in conjunction with architectural applications such as Computer-Aided Design (CAD) and give the architect creative responses that he would not achieve in any other way. Shape Grammars have the potential to improve projects because, even if a final solution isn't provided, the wide range of hypotheses available can be regarded as new ideas and an incentive to creativity. Shape grammars provide the architect not only an endless number of solutions (comparing the solutions he would get if he didn't use SG) but also a lot of emergent solutions that will enrich his aesthetic vocabulary.

In this article, we present our early exploration into how the use of SG can be objective help for project decisions, divided into a Methodology section with two sub-sections: 2.1. Decision-Making in the Architectural Project Concerning Shape Grammars and 2.2. Problem Solving with Shape Grammars. In sub-section 2.1., we present how SG can provide various and emergent solutions to architectural problems. Since architectural projects must address a large number of complex problems and intentions, SG can be a method for the search and test of more solutions than the ones the designer could explore without them. In sub-section 2.2., we demonstrate a list of architectural problems that can be objectively answered by SG, helping the architect to explore new creative ways and obtain better results by the test of a larger variety of solutions. Being able to identify a set of phases in the architectural project that represent issues whose solutions involve technical and aesthetic rules, we can define SG with rules to be followed that will allow the architect to get a wider range of responses. Our objective is to show how SG can respond to very concrete questions that exist in the architectural project.

\section{Methodology}

\subsection{Decision-Making in the Architectural Project Concerning Shape Grammars}

Digital Design and CAD applications are widely used today in architectural projects and design. As far as creative areas are concerned, computational applications have meant much faster and more effective processes compared to those previously done. They have also allowed the production of more complex and ambitious projects, offering new ways of analysis, control and representation that wouldn't be otherwise available to designers, saving time and perhaps unaffordable resources. The architect is responsible for the definition of an individual style of architecture, his own style [11], connected with his intentions and purposes, which might have aesthetic concerns or others. From this point of view, the style is related to the idea of the purposes of the design and to the way the artist resolves a certain problem.

Having highlighted the connection between style and problem solving, we should also realize that there is a link between creativity and hypothesis exploration, which leads to the possibility of a wider range of results through the use of SG. Gero points out that creativity resides not only in a new artifact evaluated by society but also in the processes that have potential to generate artifacts that might be evaluated as creative [12]. The designer deals with a very specific context, with special features, and the perception of the purposes, restrictions and contexts that enable him to explore relationships and solutions in an individual and creative way.

When a designer defines SG, defining a set of rules and a shape vocabulary, which can be translated into solutions to a certain problem, he generates the principles that will lead the generative process. This process has a trial and error component as it goes through several hypotheses until an acceptable solution is found. This possible formal solution may not correspond exactly either to the intention or to the planned purpose in the beginning of the process. There can be some lack of control of the outcome, as the generative process might lead to unsuspected results. Mayer pointed out that this lack of control, as a restriction to the expansion of SG in practical applications [11], could be an advantage and opportunity in the development of new solutions to the project issues in architecture and design.

Architectural projects, in contrast to other artistic areas, develop in different phases that can be described not only as a need to solve a lot of issues but also the fulfilment of legal, environmental, economic or formal rules and restrictions. It's in the solution of all these issues that the final project comes out, and the architect shows his creativity, combining all these items in an aesthetic and functional product. If the architect has to respond to challenges, he will look for the ideal solution and follow the recipes that he has already tested and evaluated in his past practice. Therefore, his creativity might be conditioned to his experience or to the lack of time/tools to explore and test the new hypothesis without assurance of success [13].

From our point of view, this way of using SG doesn't bring any problems in terms of creativity and authorship. The architect will have to consider the rules he has or intends to fulfil for each problem or sub-problem and which shape vocabulary will be involved. He will then be the author and controller of the SG that will respond to the problem.

The use of SG leads to emergency. An architect may find an ideal solution through the use of SG that he has created solving a problem that he had not predicted. Even if emergencies arise that are not validated, the architect can use them as new ideas, whether by denial or acceptance of the 
forms generated. Even the non-validation of an emergency allows the architect to restrict the range of hypotheses and gain new settings to the desired solution. This work of testing and validating solutions given by the created SG is the procedure that defines a creative process of synergy between SG and the architect, allowing the final solution of the project to be potentially improved and unique as well, or, at least, different from what the architect would accomplish without the use of SG [14].

\subsection{Problem Solving with Shape Grammars}

An overwhelming majority of architectural projects have situations that are common and also project-specific that can be dealt with by the use of SG. Architecture, in its essence, is made of shapes, spaces and relationships. There is a great deal of themes that can be explored by the architect to create his work [15], even if they are carefully planned or created intuitively. Themes such as relationships between weight and shapes, full and empty spaces, light and shadow, conjugations between similar shapes and/or dissimilar shapes can be recognized in every architectural work and help people understand and define it. On the other hand, an architectural work is deeply connected with social and legal rules. Every project has to respond to objective rules and to urban laws that sometimes confine the development of the solution. The following examples are representative of the extensive use of SG and how they can be used in order to achieve solutions or to develop new ideas. Rules applied in each situation will be presented in these examples. It's also important to stress that the architect can insert some others if he wants to. We intend to show how SG can be applied in common phases of the overwhelming majority of urban and building projects.

\section{Definition of Rules for Buildings, Public Spaces and Circulation Ways}

There are a great variety of common architectural rules that can be demonstrated in Figure 1. These rules present orthogonal definitions for buildings and circulation ways. Other rules can be defined such as radial intention (as can be seen in some cities) or be extrapolated to emerging buildings, through a wide range of shape alphabet relationships between them.

\section{Implantation Polygon in the Lot}

Having a lot to build on, an implantation polygon of the building (Figure 2) has to obey a set of rules as mentioned above, and should include choices concerning the building shape. The implantation area has to consider the number of floors of the building: the larger the number of floors, the smaller the implantation area. It should also take into account the organizational logic of the inner spaces, affecting its outer boundary line.
Rule 1

Distance between lots and distribution<smiles>C1CCCCCC1</smiles>

Rule 2

Definition of circulation 'way's and public spaces

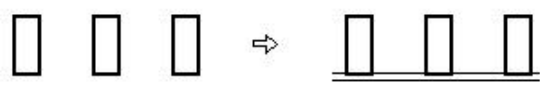

Rule 3

Definition of multiple lots joining

circulation 'way's and public spaces
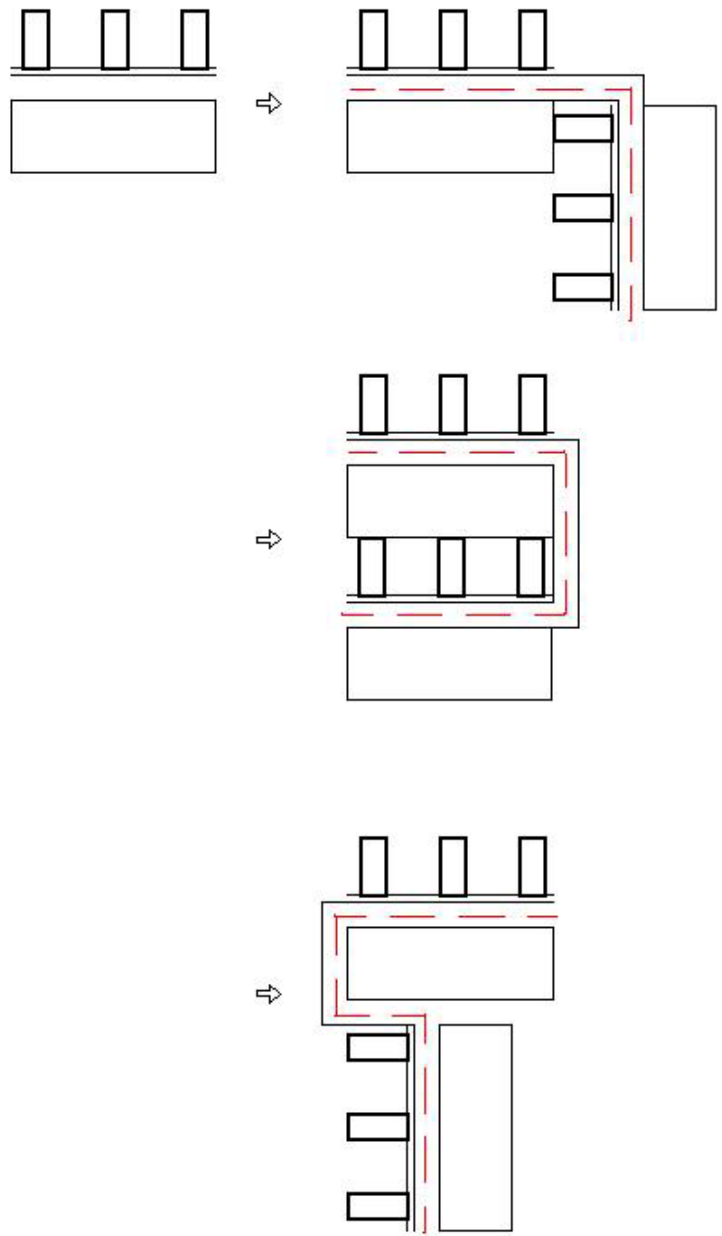

Figure 1. Lot Distribution, created by the authors to demonstrate the use of SG. 
Rule 1

Implantation in the lot with

pre-defined polygon

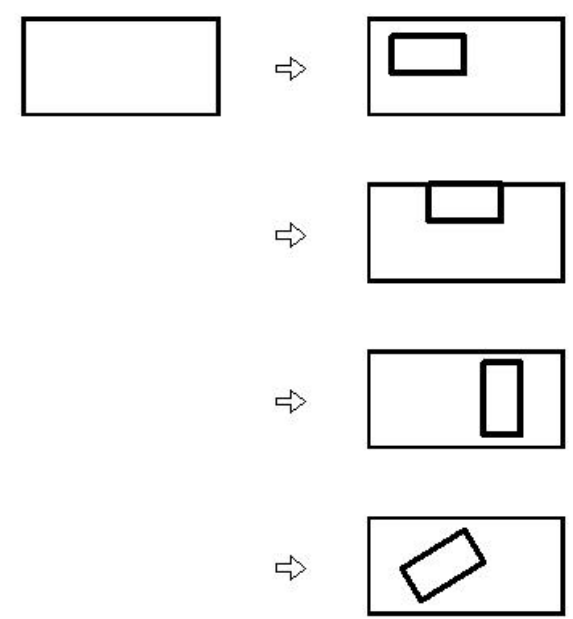

Rule 2

Implantation in the lot with area $X$ and number of faces $Y$

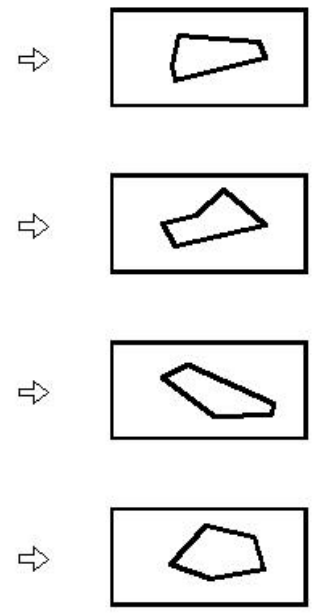

Figure 2. Implantation Polygon, created by the authors to demonstrate the use of SG.

\section{Integration in the Lot - Compatibility with Terrain Curves}

Today, since there are computational applications to help the architect study the best integration of the building in the lot (Figure 3), minimizing the movement of the top surface and facilitating the construction, the architect's goals might be defined as SG rules, such as taking advantages of the landscape that can be seen from the lot, favoring high or low areas, and the shape of the level curves, which can then be a graphic source to combine lines that will define the shape of the building.

\section{Rule 1}

Integration in the terrain

according to altimetry data
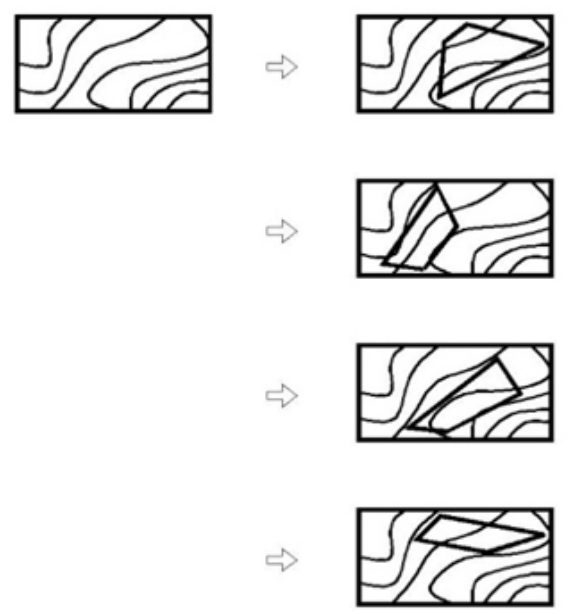

Figure 3. Integration with the terrain, created by the authors to demonstrate the use of SG.

\section{Circulation Ways}

The definition of SG rules to plan the circulation ways, as presented in Figure 4, can be related, on a larger scale, with the definition of the lot organization, and on a smaller scale, with the definition of the inner communication areas of the building, helping its drawing outline the inner space organization.

Rule 1

Definition of

circulation ways
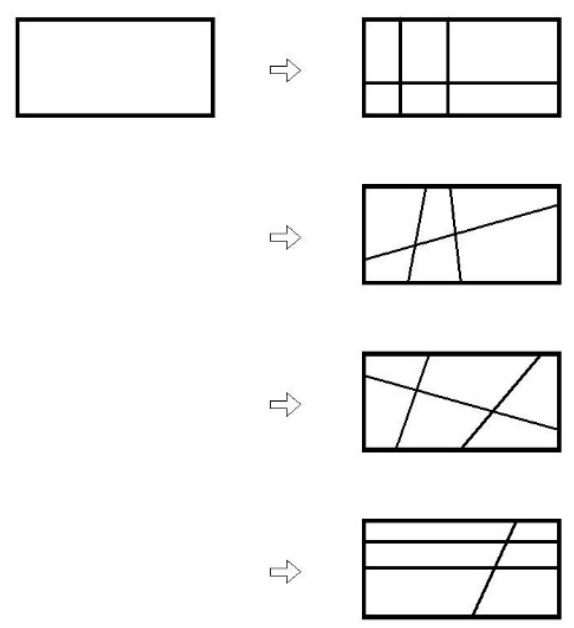

Figure 4. Circulation ways, created by the authors to demonstrate the use of SG. 


\section{Garden Design}

We can apply the rules of division of lots and those of circulation ways (Figure 5), using SG that will guarantee that the building areas have the green spaces required and being at the same time formal and unique. In the landscaped areas, rules might be defined to plan the distribution of floral and arboreal elements, which might also define aesthetic shapes.

\section{Shapes Alphabet - Symbols for plan:'s type}

Tree Type 1 Tree Type 2 Bush Type 1

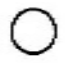

\section{$\mathrm{O}$}

Rule 1

Distribution of one Tree Type 1

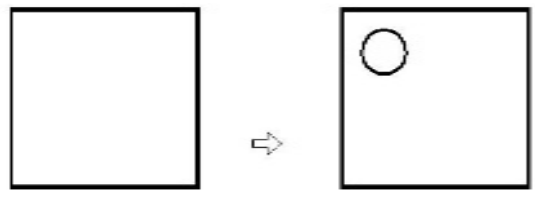

Rule 2

Distribution of two Trees Type 2 foe each Tree Type 1

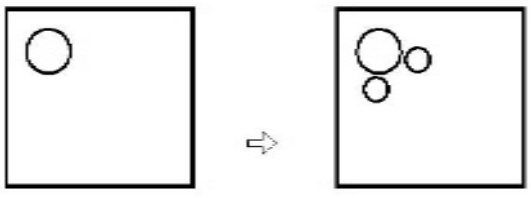

Rule 3

Distribution of three Bushes Type 1 near TRees Type 2
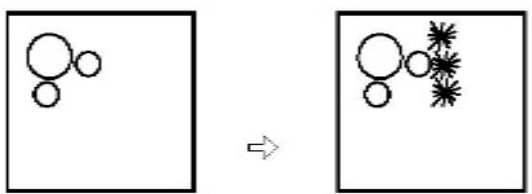

Figure 5. Garden Design, created by the authors to demonstrate the use of SG.

\section{Lot division}

The division of the lots follows a wide range of legal rules such as maximum areas of land occupation, distance between surrounding buildings, dimension of circulation ways, green space areas, public space areas, among others. In short, these rules, together with the rules the architect intends to insert concerning the shape of the buildings and the relationships between them, may generate SG that will set the shape distribution in the lot and at the same time define the lot occupation.

\section{Balconies Definition}

Being important spaces, as they connect the inner side to the outer side of the building, balconies are elements that have an effect on the shape of the building and on its relationship with the surroundings. Stressing the aesthetic aspects, SG may define rules that will generate balcony designs on the "building shell", matching technical rules such as maximum suspended area and formal aspects such as exploiting the sights.

\section{Floor Design}

Floor design can change from floor to floor. It can be a regular or irregular design, depending on the geometric design we want. Geometric designs can respond to SG rules relating to the interior organization, to the need of distinguishing areas, or for instance, to separation of flats. This might also consider the balconies mentioned above and the optimization of a glassed area if people want to enjoy the surroundings.

\section{Interior Space Organization}

Interior space organization depends on a wide range of rules related to the building typology and its needs (hotel, hospital, housing, school; each of these has a set of specific rules). All the objective and aesthetic goals could be added in with SG to regulate the expected shape.

\section{Design of Façade Openings}

The design of the façade openings, taking the aspects of floor design mentioned above into account, might be based on SG rules, such as the definition of the maximum glassed area for each division of the building. They might follow thermal rules that will guarantee the solar access and shadowing, and geometric rules as well that will lead to certain aesthetics of the building.

\section{Formal Combination of Materials}

The materials used on façades or in the inner spaces might be included in the subject of graphic, formal/creative spaces, which can then be defined by SG. Following the same logic of the examples described above, different project phases and issues can be discovered, which then can also be solved through the use of SG. The architectural project gains its identity on the idea developed by the architect and in the creativity through which he solves the issues. He also has to obey a wide range of rules. Overall, the architect's intentions are per se rules, which are not imposed by technical and legal needs of the project but rather by the artist's aesthetic and creative intentions. Dividing the project into its elementary parts, we see that the architect elects, consciously or intuitively, a set of rules and makes choices that are responsible for the final work. Thus, SG can explain design styles, once the rules, which generate a certain shape, are recognized. 


\section{Conclusions}

The architect has been changing the way of doing his job since the advent of the computer. He can now use computational applications to reproduce and automatically generate the designs of his architectural projects in the simulation of tridimensional models. It is now possible to explore multiple hypotheses, reducing project errors and spending less time in searching for more complex solutions to achieve more ambitious, innovative and creative projects. With the development of AI, and within this area, the growth of applications to simulate creativity, architectural projects gained computational applications that boost not only the technical aspects but also the creative and aesthetic ones. It's now common practice to use computational applications, which reproduce the architect's manual design, among other technical aspects of the project (such as automatic measurements, thermal simulations, three-dimensional visualization, etc.). And in the same but novel way, we show how architects may use SG and its applications as a common practice and a way of optimizing his ideas, using not only Computational Design but also Computational Creativity [16].

Our future work aims to help SG implementations to effectively enter in the design practice and become a relevant way of exploring ideas and design solutions. Having in mind the paradigm of the use of SG in the design process, we want to propose a model to address the interface issues related to the use of SG by architects, designer, artist and students, as they all interact differently and with different purposes [17].

\section{REFERENCES}

[1] Maher, Mary Lou. 2008. “Creativity, Computation, and Interaction”. University of Sydney and National Science Foundation.

[2] Gips, J. e Stiny, G. 1975. "Shape grammars and their uses artificial perception, shape generation, and computer aesthetics”. ISBN 978-3-0348-5753-6. Birkhauser.

[3] Southerland I. 1963. "Sketchpad: A man-machine graphical communication system.” MIT Lincolm Lab. Tech. Rept.
$\mathrm{N}^{\circ} 296$, Lexington. MA. Computing Machinery Special Interest Group on Computer Graphics, A.C.M. New Youk.

[4] Mitchell, W. 1975. The theoretical foundation of computer aided architectural design. Environment and Planning B, v.2, p.127-150.

[5] Stiny, G 1980. Introduction to shape and shape grammars. Environment and Planning B: Planning and Design 7 343-351.

[6] Stiny, G. 1885. "Computing with form and meaning in architecture”. Journal of Architectural Education 39, 7-19.

[7] Terzidis, K. 2006. “Algorithmic architecture”. Elsevier, Oxford.

[8] Post, E. 1943. “General Combinatorial Decision Problem”. American Journal of Mathematics 65: 197-215.

[9] Chomsky, N. 1972. "Language and Mind. New York: Harcourt, Brace, Jovanovich

[10] Krishnamurti, R. 1980. "The arithmetic of shapes". Envronment and Planning B: Planning and Design 7 463-484.

[11] Mayer, R. e Turkienicz, B. 1978. “Cognitive Process, Styles and Grammars, The cognitive approach applied to Nie-meyer's free forms”. eCAADe 23 - session 11: shape grammars, 529-536

[12] Gero, J. S. 2006. “Creativity, emergence and evolution in design: concepts and framework”. Knowledge-Based Systems 9(7): 435-448.

[13] Carroll, J. M. 2003. "HCI Models, Theories and Frameworks”. San Francisco: Morgan Kaufmann Publishers

[14] McKay, A., Chase, S. C., Garner, S. W., Jowers, I., Prats, M., Hogg, D. C., Lim, S. 2009. "Design Synthesis and Shape Generation”. Designing for the 21st Century: Interdisciplinary Methods and Findings, 304-321.

[15] Consiglieri, Victor. 1994. “A Morfologia da Arquitectura”. Vol. I e II, Editorial Estampa.

[16] Economou, A., and Kotsopoulos S., "From Shape Rules To Rule Schemata And Back”, Design Computing and Cognition DCC'14. Eds: J. S. Gero and S. Hanna, Springer, pp. 419-438, 2014

[17] Tching, J., Reis, J., \& Paio, A. 2016. “A Cognitive Walkthrough towards an Interface Model for Shape Grammar Implementations”. Journal of Computer Science and Information Technology, 4(3): 92-119, 2016 